\title{
Effect of Nesiritide in Patients with Acute Decompensated Heart Failure
}

\author{
C.M. O'Connor, R.C. Starling, A.F. Hernandez, P.W. Armstrong, K. Dickstein, \\ V. Hasselblad, G.M. Heizer, M. Komajda, B.M. Massie, J.J.V. McMurray, \\ M.S. Nieminen, C.J. Reist, J.L. Rouleau, K. Swedberg, K.F. Adams, Jr., \\ S.D. Anker, D. Atar, A. Battler, R. Botero, N.R. Bohidar, J. Butler, N. Clausell, \\ R. Corbalán, M.R. Costanzo, U. Dahlstrom, L.I. Deckelbaum, R. Diaz, \\ M.E. Dunlap, J.A. Ezekowitz, D. Feldman, G.M. Felker, G.C. Fonarow, \\ D. Gennevois, S.S. Gottlieb, J.A. Hill, J.E. Hollander, J.G. Howlett, M.P. Hudson, \\ R.D. Kociol, H. Krum, A. Laucevicius, W.C. Levy, G.F. Méndez, M. Metra, \\ S. Mittal, B.-H. Oh, N.L. Pereira, P. Ponikowski, W.H.W. Tang, S. Tanomsup, \\ J.R. Teerlink, F. Triposkiadis, R.W. Troughton, A.A. Voors, \\ D.J. Whellan, F. Zannad, and R.M. Califf
}

The authors' full names, degrees, and affiliations are listed in the Appendix. Address reprint requests to Dr. O'Connor at the Duke Clinical Research Institute, Duke University Medical Center, Box 3356, Durham, NC 27710, or at oconn002@ mc.duke.edu.

This article (10.1056/NEJMoal100171) was updated on July 12, 2011 at NEJM.org.

N EnglJ Med 2011;365:32-43.

Copyright (c) 2011 Massachusetts Medical Society.

\section{ABSTRACT}

\section{BACKGROUND}

Nesiritide is approved in the United States for early relief of dyspnea in patients with acute heart failure. Previous meta-analyses have raised questions regarding renal toxicity and the mortality associated with this agent.

METHODS

We randomly assigned 7141 patients who were hospitalized with acute heart failure to receive either nesiritide or placebo for 24 to 168 hours in addition to standard care. Coprimary end points were the change in dyspnea at 6 and 24 hours, as measured on a 7-point Likert scale, and the composite end point of rehospitalization for heart failure or death within 30 days.

\section{RESULTS}

Patients randomly assigned to nesiritide, as compared with those assigned to placebo, more frequently reported markedly or moderately improved dyspnea at 6 hours $(44.5 \%$ vs. $42.1 \%, \mathrm{P}=0.03)$ and 24 hours $(68.2 \%$ vs. $66.1 \%, \mathrm{P}=0.007)$, but the prespecified level for significance ( $\mathrm{P} \leq 0.005$ for both assessments or $\mathrm{P} \leq 0.0025$ for either) was not met. The rate of rehospitalization for heart failure or death from any cause within 30 days was $9.4 \%$ in the nesiritide group versus $10.1 \%$ in the placebo group (absolute difference, -0.7 percentage points; $95 \%$ confidence interval [CI], -2.1 to $0.7 ; \mathrm{P}=0.31$ ). There were no significant differences in rates of death from any cause at 30 days (3.6\% with nesiritide vs. $4.0 \%$ with placebo; absolute difference, -0.4 percentage points; $95 \% \mathrm{CI},-1.3$ to 0.5 ) or rates of worsening renal function, defined by more than a $25 \%$ decrease in the estimated glomerular filtration rate $(31.4 \%$ vs. $29.5 \%$; odds ratio, 1.09; 95\% CI, 0.98 to $1.21 ; \mathrm{P}=0.11$ ).

\section{CONCLUSIONS}

Nesiritide was not associated with an increase or a decrease in the rate of death and rehospitalization and had a small, nonsignificant effect on dyspnea when used in combination with other therapies. It was not associated with a worsening of renal function, but it was associated with an increase in rates of hypotension. On the basis of these results, nesiritide cannot be recommended for routine use in the broad population of patients with acute heart failure. (Funded by Scios; ClinicalTrials.gov number, NCT00475852.) 
CUTE DECOMPENSATED HEART FAILURE is a major health problem that is associated with several million hospitalizations worldwide each year, poor short-term outcomes, and high costs. ${ }^{1-3}$ Despite the magnitude of the problem, rates of early death and rehospitalization have not improved over the past several decades. ${ }^{3}$

Nesiritide, a recombinant B-type natriuretic peptide (BNP) with vasodilatory properties, ${ }^{4-7}$ was approved in 2001 for use in patients with acute heart failure on the basis of studies showing a reduction in pulmonary-capillary wedge pressure and improvement in dyspnea at 3 hours. ${ }^{5,6,8}$ However, subsequent pooled analyses of data from small, randomized trials suggested that nesiritide, as compared with placebo, was associated with a rate of worsening renal function that was increased by a factor of 1.5 and a rate of early death that was increased by a factor of 1.8 , although the confidence intervals associated with these estimates were wide. ${ }^{9,10}$

An independent panel convened to evaluate this issue recommended that a large clinical trial be conducted to answer the question of whether nesiritide is effective and safe. ${ }^{11}$ Accordingly, the Acute Study of Clinical Effectiveness of Nesiritide in Decompensated Heart Failure (ASCEND-HF) trial was designed to evaluate the effect of nesiritide, in addition to standard care, on rates of selfreported dyspnea at 6 and 24 hours, rehospitalization for heart failure or death from any cause at 30 days, and renal dysfunction.

\section{METHODS}

\section{STUDY DESIGN AND OVERSIGHT}

The ASCEND-HF was a randomized, double-blind, placebo-controlled trial of nesiritide in addition to standard care. The study design has been published elsewhere, ${ }^{12}$ and the study protocol is available with the full text of this article at NEJM.org. The trial was conducted from May 2007 through August 2010 at 398 centers throughout the world. The study was approved by each participating center's ethics committee or institutional review board, and all participants provided written informed consent. Research sites in North America were managed by a consortium of academic research organizations that included the Canadian VIGOUR Centre, the Cleveland Clinic's C5 Research Group, the Duke Clinical Research Institute, the Henry Ford Coordinating Center, and the Jefferson Coordinating Center for Clinical Research.
The Duke Clinical Research Institute performed study-data processing and statistical analyses, and the Duke Clinical Research Institute, a network of academic research organizations, and Johnson \& Johnson Pharmaceutical Research and Development managed the study at the participating sites. The executive committee was responsible for the trial design, and the steering committee supervised patient recruitment and clinical management of the trial. Before the database was locked, only the drug-distribution group and the data and safety monitoring board maintained the code for group assignments. The manuscript was initially drafted by the academic authors, and it was written independently of the sponsor by the executive and steering committees. The sponsor was allowed to comment on the manuscript before submission, but all final decisions were made by the executive committee. An independent data and safety monitoring board met after every 1000 patients had been recruited, and statistical analyses were conducted by Frontier Science and Technology Research Foundation independently of the sponsor.

After the database was locked, the sponsor and executive committee were made aware of potential quality issues at one site that had randomly assigned 121 patients to a study group. The site used duplicate copies of electrocardiographic tracings as data for more than one subject or subject visit date. Additional statistical analyses performed to determine whether other data were potentially affected did not identify any other data abnormalities. Since this information was obtained after the database was locked and the overall study results were unblinded, and sensitivity analyses censoring data from this site showed no material change in the efficacy or safety analyses or conclusions, the decision was made not to alter the data sets in the primary analysis. The first author vouches for the completeness and accuracy of the data and the analyses as well as the fidelity of the study to the protocol.

\section{STUDY PATIENTS}

Patients were eligible to participate in the study if they were hospitalized for heart failure occurring within 24 hours before they received their first intravenous treatment for heart failure or if they had received a diagnosis of acute decompensated heart failure less than 48 hours after hospitalization for another cause and underwent randomization within 24 hours after intravenous treatment for heart failure. Additional criteria at the time of 
randomization included the following: dyspnea at rest or with minimal activity, one or more accompanying signs (respiratory rate $\geq 20$ breaths per minute or pulmonary congestion or edema with rales one third of the way or more up the lung fields), and one or more objective measures of heart failure (evidence of congestion or edema on chest radiography, a BNP level $\geq 400$ pg per milliliter or an N-terminal pro-BNP level $\geq 1000 \mathrm{pg}$ per milliliter, pulmonary-capillary wedge pressure $>20 \mathrm{~mm} \mathrm{Hg}$, or left ventricular ejection fraction $<40 \%$ in the previous 12 months). ${ }^{12}$

Key exclusion criteria were a high risk of hypotension (systolic pressure $<100 \mathrm{~mm} \mathrm{Hg}$ or $110 \mathrm{~mm} \mathrm{Hg}$ with the use of intravenous nitroglycerin), other contraindications for vasodilators, treatment with dobutamine (at a dose $\geq 5 \mu \mathrm{g}$ per kilogram of body weight per minute), treatment with milrinone or levosimendan within the previous 30 days, persistent uncontrolled hypertension, acute coronary syndrome, normal level of BNP or $\mathrm{N}$-terminal pro-BNP, severe pulmonary disease, end-stage renal disease during receipt of renalreplacement therapy, and clinically significant anemia. Complete eligibility criteria are described elsewhere ${ }^{12}$ and in the study protocol.

\section{STUDY-DRUG ADMINISTRATION}

Eligible patients were randomly assigned in a 1:1 ratio to receive nesiritide or placebo. All participants received standard therapies, including diuretics, morphine, and other vasoactive medications, as determined by the investigator with the guidance of a standard-of-care manual. ${ }^{13}$ After a recommended but optional intravenous bolus of nesiritide, at a dose of $2 \mu \mathrm{g}$ per kilogram (administered at the discretion of the investigator), nesiritide was administered as a continuous infusion of $0.010 \mu \mathrm{g}$ per kilogram per minute for 24 hours or more for up to 7 days.

\section{END POINTS}

The study had two coprimary end points: the change in self-reported dyspnea 6 and 24 hours after study-drug initiation and the composite end point of rehospitalization for heart failure and death from any cause during the period from randomization to day 30. Dyspnea was measured with the use of a self-reported 7-point categorical Likert scale, ranging from "markedly better" to "markedly worse," as compared with the degree of dyspnea present at the start time of study-drug ad- ministration. Rehospitalization and fatal events within 30 days after randomization were reviewed and categorized by an independent, blinded clinical-events committee at the University of Glasgow. The following criteria were required for hospitalization events to be classified as due to heart failure: typical clinical manifestations of worsening heart failure and the addition of (or increase in) treatment specifically for worsening heart failure with an intravenous pharmacologic agent, or mechanical or surgical intervention or ultrafiltration, hemofiltration, or dialysis specifically for management of persistent or worsening heart failure. Hospitalized patients who remained in the hospital at 30 days because of heart failure were counted as being rehospitalized for heart failure in the analysis of the coprimary end point.

Secondary end points included self-reported overall well-being, measured 6 and 24 hours after study-drug initiation with the use of the 7-point Likert scale, the composite end point of persistent or worsening heart failure and death from any cause during the period from randomization through hospital discharge (index hospitalization), the number of days alive and out of the hospital through day 30 , and the composite end point of death from cardiovascular causes and rehospitalization due to cardiovascular causes from randomization through day 30 .

Safety end points included death from any cause during the period from randomization through day 30; death from cardiovascular causes; sudden death from cardiac causes through day 30 ; need for renal replacement therapy (defined by $>25 \%$ decrease from the baseline estimated glomerular filtration rate, calculated with the use of the simplified Modification of Diet in Renal Disease equation) at any time from study-drug initiation through day 30; and the occurrence of investigator-reported hypotension relative to the participant's baseline blood pressure through hospital discharge or 10 days after study-drug initiation, whichever occurred first.

\section{STATISTICAL ANALYSIS}

Calculation of the sample size was based on the composite end point of rehospitalization for heart failure or death from any cause through day 30 . The planned enrollment of 7000 patients was estimated to provide $89 \%$ power, with the use of the chisquare test and a two-sided alpha level of 0.045 , to detect a difference between groups, assuming an 
event rate of $11.4 \%$ in the nesiritide group and an event rate of $14.0 \%$ in the placebo group (relative risk reduction, 18.6\%). For the dyspnea end point, this sample size was estimated to provide $99 \%$ power, with the use of the Wilcoxon rank-sum test and a two-sided alpha level of 0.0025 , to detect an effect size of 0.543 between the nesiritide and placebo groups (translating to a 54.3\% probability that a patient receiving nesiritide would report a better outcome than a patient receiving placebo).

The differences between study drugs with respect to the binary composite end point and the renal end points were estimated with the use of the Cochran-Mantel-Haenszel test, stratified according to region. Hypotension was compared between treatment groups with the use of a chi-square test. Ordinal variables (scores on the Likert scale) were compared with the use of the van Elteren test, ${ }^{14}$ with adjustment for region. The numbers of days that patients were alive and out of the hospital were assessed with the use of analysis of variance, with adjustment for region.

Differing views on the part of regulators in the United States and Europe regarding the primacy of end points led to the creation of two analysis plans. The primary analysis plan tested the coprimary end points with the use of a Bonferroni approach. The composite of rehospitalization for heart failure and death from any cause at day 30 was tested at the 0.045 significance level, and the assessments of dyspnea at 6 and 24 hours were tested at the 0.005 level with the use of the Hochberg method. The dyspnea end point was considered significant if the $P$ values were $\leq 0.005$ at both 6 and 24 hours, or if either of the two P values was $\leq 0.0025$. If the coprimary composite efficacy end point was significant at the specified level of 0.045 , the analysis of the secondary end points was to be performed sequentially at an alpha level of 0.045 with the use of closed-testing principles (or 0.05 as specified by the European Medicines Agency).

The European Medicines Agency considered the dyspnea end points to be primary efficacy end points and rehospitalization for heart failure (combined with mortality) to be a secondary end point, so that Bonferroni correction was not part of the analysis plan required by that agency. Thus, for the regulatory purposes of the European Medicines Agency, the primary end points were dyspnea alone at 6 and 24 hours, and these end points were tested at an alpha level of 0.05 with the use of the Hochberg method, with statistical signifi- cance indicated by a P value of 0.05 or less for both the 6- and 24-hour assessments or by a P value of 0.025 or less for one of the assessments.

The following prespecified subgroup analyses were performed to evaluate the homogeneity of treatment effects on primary and secondary end points: geographic region; use or nonuse of a study-drug bolus; use or nonuse of an inotropic agent, intravenous vasodilator, or intravenous nitroglycerin at randomization; use or nonuse of a diuretic from the onset of the qualifying episode of heart failure through randomization; sex; age; race or ethnic group; baseline renal function, ejection fraction, and systolic blood pressure; and presence or absence of a history of coronary artery disease or diabetes mellitus.

Primary efficacy analyses and safety analyses were performed for the modified intention-to-treat population, defined as all randomly assigned participants who received any amount of study medication. Efficacy analyses were conducted according to randomized treatment assignment; safety analyses were conducted according to actual treatment received. All statistical analyses were performed with the use of SAS software, version 9.2 (SAS Institute).

\section{RESULTS}

\section{PATIENT POPULATION}

From May 2007 through August 2010, a total of 7141 patients underwent randomization at 398 sites in North America, Europe, Latin America, and the Asia-Pacific region. Of these participants, 7007 (98\%) received a study drug (3496 patients assigned to nesiritide and 3511 assigned to placebo) and were included in the modified intention-to-treat analysis (Fig. S1 in the Supplementary Appendix, available at NEJM.org). The study groups were well balanced and similar in all respects (Table 1) and similar to the intention-to-treat group.

\section{COPRIMARY END POINTS}

The distribution of patient-reported assessments of dyspnea at 6 and 24 hours is shown in Figure 1A. Although a small increase in the number of patients reporting improvement in dyspnea was observed at both the 6-and 24-hour time points, this finding did not meet the prespecified criteria for significance.

Rehospitalization for heart failure or death from any cause at 30 days (Fig. 1B) occurred in 
321 patients in the nesiritide group (9.4\%) as compared with 345 patients in the placebo group (10.1\%) (absolute difference, -0.7 percentage points; $95 \%$ confidence interval [CI], -2.1 to 0.7 ;
$\mathrm{P}=0.31$ ). Individual components of the primary end point are shown in Table 2. The time-to-event analysis showed similar results for the composite end point, with a hazard ratio for death from any

Table 1. Characteristics of the Modified Intention-to-Treat Population.*

\begin{tabular}{|c|c|c|}
\hline Characteristic & $\begin{array}{l}\text { Nesiritide } \\
(\mathrm{N}=3496)\end{array}$ & $\begin{array}{l}\text { Placebo } \\
(\mathrm{N}=3511)\end{array}$ \\
\hline \multicolumn{3}{|l|}{ Age - yr } \\
\hline Median & 67 & 67 \\
\hline Interquartile range & $56-76$ & $56-76$ \\
\hline \multicolumn{3}{|l|}{ Sex - no./total no. (\%) } \\
\hline Female & $1167 / 3496(33.4)$ & $1224 / 3511(34.9)$ \\
\hline Male & $2329 / 3496(66.6)$ & $2287 / 3511(65.1)$ \\
\hline \multicolumn{3}{|l|}{ Race - no./total no. (\%) † } \\
\hline White & $1964 / 3496(56.2)$ & $1952 / 3511(55.6)$ \\
\hline Black & $513 / 3496(14.7)$ & $527 / 3511(15.0)$ \\
\hline Asian & $873 / 3496(25.0)$ & $874 / 3511(24.9)$ \\
\hline Other & $145 / 3496(4.1)$ & $158 / 3511(4.5)$ \\
\hline \multicolumn{3}{|l|}{ Systolic pressure - $\mathrm{mm} \mathrm{Hg}$} \\
\hline Median & 123 & 124 \\
\hline Interquartile range & $110-140$ & $110-140$ \\
\hline \multicolumn{3}{|l|}{ Heart rate at rest - beats/min } \\
\hline Median & 82 & 82 \\
\hline Interquartile range & $72-95$ & $72-95$ \\
\hline \multicolumn{3}{|l|}{$\mathrm{BNP}-\mathrm{pg} / \mathrm{ml}+$} \\
\hline Median & 994 & 989 \\
\hline Interquartile range & 544-1925 & $543-1782$ \\
\hline \multicolumn{3}{|l|}{ N-terminal pro-BNP - pg/mld } \\
\hline Median & 4508 & 4461 \\
\hline Interquartile range & $2076-9174$ & $2123-9217$ \\
\hline \multicolumn{3}{|l|}{ Creatinine $-\mathrm{mg} / \mathrm{dl}$} \\
\hline Median & 1.2 & 1.2 \\
\hline Interquartile range & $1.0-1.5$ & $1.0-1.6$ \\
\hline \multicolumn{3}{|l|}{ Serum sodium - $\mathrm{mmol} / \mathrm{liter}$} \\
\hline Median & 139 & 139 \\
\hline Interquartile range & $136-141$ & $136-141$ \\
\hline \multicolumn{3}{|c|}{ Left ventricular ejection fraction within previous $12 \mathrm{mo}$ - no./total no. (\%) 9} \\
\hline$<40 \%$ & $2127 / 2632(80.8)$ & $2106 / 2649(79.5)$ \\
\hline$\geq 40 \%$ & $505 / 2632(19.2)$ & $543 / 2649(20.5)$ \\
\hline \multicolumn{3}{|l|}{ Medical history — no./total no. (\%) } \\
\hline Heart failure $1 \mathrm{yr}$ before admission & $1339 / 3492(38.3)$ & $1386 / 3508(39.5)$ \\
\hline Ischemic heart disease & $2081 / 3496(59.5)$ & $2133 / 3511(60.8)$ \\
\hline Hypertension & $2510 / 3496(71.8)$ & $2548 / 3511(72.6)$ \\
\hline Atrial fibrillation or flutter & $1306 / 3496(37.4)$ & $1322 / 3511(37.7)$ \\
\hline
\end{tabular}




\begin{tabular}{|c|c|c|}
\hline Characteristic & $\begin{array}{l}\text { Nesiritide } \\
(\mathrm{N}=3496)\end{array}$ & $\begin{array}{c}\text { Placebo } \\
(\mathrm{N}=3511)\end{array}$ \\
\hline \multicolumn{3}{|l|}{ Medical therapy before randomization — no./total no. (\%) } \\
\hline ACE inhibitor or ARB & $2088 / 3496(59.7)$ & $2168 / 3510(61.8)$ \\
\hline Beta-blocker & $2005 / 3496(57.4)$ & $2069 / 3510(58.9)$ \\
\hline Aldosterone blocker & $960 / 3496(27.5)$ & $990 / 3511(28.2)$ \\
\hline Nitrate (oral or topical) & $823 / 3496(23.5)$ & $829 / 3511(23.6)$ \\
\hline Digoxin or digitalis glycoside & $933 / 3495(26.7)$ & $929 / 3511(26.5)$ \\
\hline Hydralazine & $261 / 3496(7.5)$ & $257 / 3511(7.3)$ \\
\hline Loop diuretic & $3316 / 3496(94.9)$ & $3347 / 3511(95.3)$ \\
\hline Inotropic agent & $151 / 3495(4.3)$ & $156 / 3510(4.4)$ \\
\hline Vasodilator & $549 / 3496(15.7)$ & $496 / 3510(14.1)$ \\
\hline \multicolumn{3}{|c|}{ Use of medication from randomization through $24 \mathrm{hr}-$ no./total no. (\%) } \\
\hline Loop diuretic & $3149 / 3496(90.1)$ & $3225 / 3511(91.9)$ \\
\hline Inotropic agent & $228 / 3495(6.5)$ & $231 / 3508(6.6)$ \\
\hline Vasodilator & $544 / 3495(15.6)$ & $511 / 3508(14.6)$ \\
\hline \multicolumn{3}{|l|}{ Time from hospitalization to randomization $-\mathrm{hr}$} \\
\hline Median & 15.3 & 15.7 \\
\hline Interquartile range & $5.4-21.9$ & $5.4-22.0$ \\
\hline \multicolumn{3}{|l|}{ Time from randomization to study-drug administration $-\mathrm{hr}$} \\
\hline Median & 0.8 & 0.8 \\
\hline Interquartile range & $0.5-1.4$ & $0.5-1.4$ \\
\hline Administration of study-drug bolus — no./total no. (\%) & $2172 / 3496(62.1)$ & $2160 / 3511(61.5)$ \\
\hline \multicolumn{3}{|l|}{ Duration of study-drug administration $-\mathrm{hr}$} \\
\hline Median & 41.0 & 43.0 \\
\hline Interquartile range & $24.1-48.3$ & $24.1-49.0$ \\
\hline
\end{tabular}

* Inotropic agents included dobutamine, dopamine, milrinone, levosimendan, vasopressin, enoximone, epinephrine, norepinephrine, and phenylephrine. Vasodilators included intravenous nitroglycerin, nitroprusside, and open-label nesiritide. To convert the values for creatinine to micromoles per liter, multiply by 88.4. BNP denotes B-type natriuretic peptide. $\dagger$ Race was self-reported.

cause or rehospitalization for heart failure of 0.93 (95\% CI, 0.80 to 1.08) (Fig. S2 in the Supplementary Appendix).

\section{SECONDARY END POINTS}

Self-reported overall well-being at 6 and 24 hours did not differ significantly between the groups (Fig. S3 in the Supplementary Appendix). In addition, no significant differences between the groups were seen with respect to the secondary end points of rehospitalization for cardiovascular causes or death from cardiovascular causes, or total days alive and out of the hospital at 30 days. The end point of persistent or worsening heart failure or death from any cause from randomization through hospital discharge (index hospitalization) was also similar between the nesiritide and placebo groups $(4.2 \%$ and $4.8 \%$, respectively; absolute difference, -0.6 percentage points; $95 \% \mathrm{CI},-1.5$ to 0.5) (Table 2).

\section{SAFETY END POINTS}

There was no significant difference between the groups with respect to the rate of death from any cause at 30 days (Table 2). A total of 126 participants who received nesiritide (3.6\%) and 141 participants who received placebo (4.0\%) died within 30 days after randomization (absolute difference, -0.4 percentage points; $95 \% \mathrm{CI},-1.3$ to 0.5 ).

There was no significant difference between the 


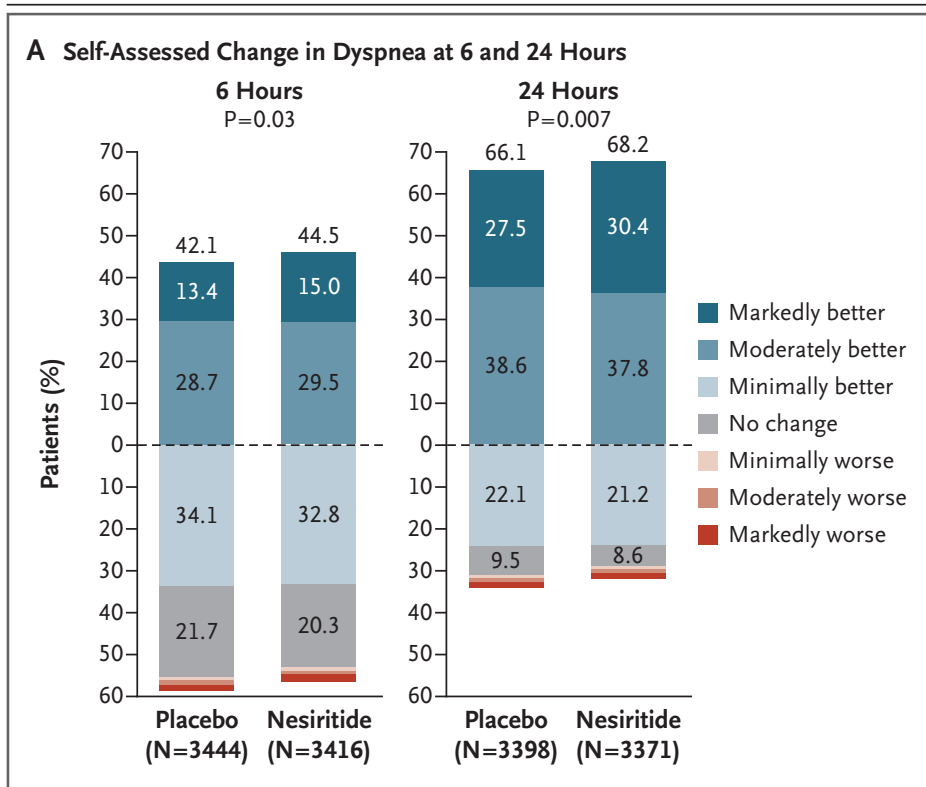

B Death from Any Cause or Rehospitalization for Heart Failure at 30 Days

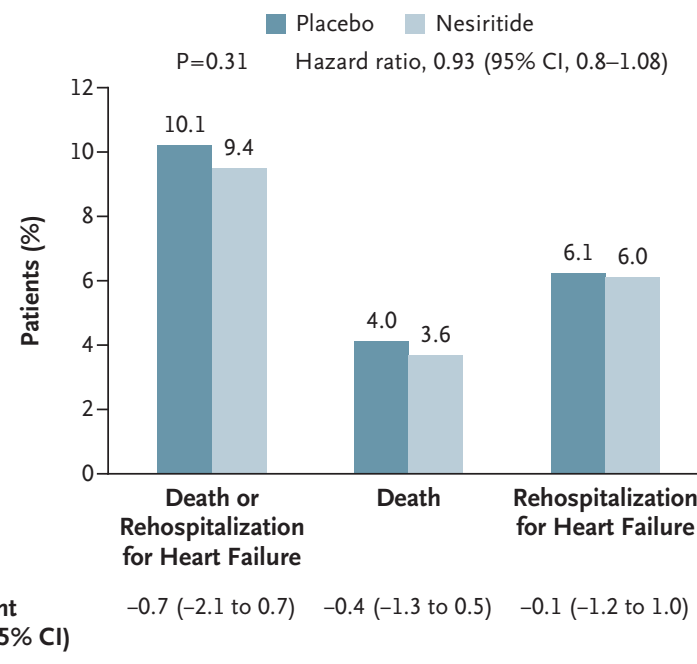

Figure 1. Changes in Dyspnea at 6 and 24 Hours and the Primary Clinical End Points at 30 Days.

In Panel A, the number above the bar indicates the overall percentage of patients who reported being markedly or moderately better after receiving study treatment (i.e., those represented by the percentages above the dashed line). siritide group than in the placebo group ( $26.6 \%$ vs. $15.3 \%, \mathrm{P}<0.001$ ), with a median systolic pressure of $80 \mathrm{~mm} \mathrm{Hg}$ (interquartile range, 70 to 87 ) during the episode among patients who received nesiritide and $80 \mathrm{~mm} \mathrm{Hg}$ (interquartile range, 70 to 85 ) among patients who received placebo. Both asymptomatic hypotension and symptomatic hypotension occurred more often in patients who received nesiritide than in patients who received placebo (asymptomatic, $21.4 \%$ vs. $12.4 \%$; symptomatic, $7.2 \%$ vs. $4.0 \%$; $\mathrm{P}<0.001$ for both comparisons) (Table 2). No significant differences in serious adverse events were observed (Table S1 in the Supplementary Appendix)

\section{SUBGROUP ANALYSES}

The coprimary outcome of rehospitalization for heart failure or death from any cause within 30 days was consistent across prespecified subgroups (Fig. 2). Likewise, the results of the subgroup analysis for the coprimary end point of self-reported dyspnea were consistent across prespecified groups (Fig. 3).

\section{DISCUSSION}

In this trial, the use of nesiritide in patients with acute decompensated heart failure neither increased nor decreased the incidence of death or rehospitalization for heart failure at 30 days. Selfreported dyspnea at 6 and 24 hours was marginally improved when nesiritide was added to conventional therapy, but this finding did not meet prespecified criteria for statistical significance. Nesiritide thus cannot be recommended in the broad population of patients with acute decompensated heart failure represented by the study population in this trial.

The effect of nesiritide on the dyspnea end point in this trial was consistent with the findings of the Vasodilation in the Management of Acute Congestive Heart Failure (VMAC; ClinicalTrials.gov number, NCT00270374) trial that formed the basis for the Food and Drug Administration's approval of nesiritide. The VMAC study included only 498 patients, and the significant effect on dyspnea at 3 hours was observed for nesiritide as compared with placebo, but this effect was similar to that of intravenous nitroglycerin, and no significant effect was detected at 24 hours. ${ }^{6}$ The VMAC protocol encouraged the withholding of additional therapy unless it was required because of worsening symptoms. Analyses in the current trial showed 


\begin{tabular}{|c|c|c|c|c|}
\hline End Point & $\begin{array}{l}\text { Nesiritide } \\
(\mathrm{N}=3496)\end{array}$ & $\begin{array}{l}\text { Placebo } \\
(\mathrm{N}=3511)\end{array}$ & $\begin{array}{l}\text { Percentage-Point } \\
\text { Difference or Odds } \\
\text { Ratio }(95 \% \mathrm{Cl}) \grave{\dagger}\end{array}$ & P Value \\
\hline \multicolumn{5}{|l|}{ Primary clinical end points } \\
\hline $\begin{array}{l}\text { Death from any cause or rehospitalization for heart failure - } \\
\text { no./total no. (\%) }\end{array}$ & $321 / 3423(9.4)$ & $345 / 3413(10.1)$ & $-0.7(-2.1$ to 0.7$)$ & 0.31 \\
\hline Death from any cause & $126 / 3490(3.6)$ & $141 / 3499(4.0)$ & $-0.4(-1.3$ to 0.5$)$ & \\
\hline Rehospitalization for heart failure & $204 / 3422(6.0)$ & $208 / 3411(6.1)$ & $-0.1(-1.2$ to 1.0$)$ & \\
\hline \multicolumn{5}{|l|}{ Secondary clinical end points } \\
\hline $\begin{array}{c}\text { Persistent or worsening heart failure or death from any cause } \\
\text { through hospital discharge - no./total no. (\%) }\end{array}$ & $147 / 3459(4.2)$ & $165 / 3462(4.8)$ & $-0.6(-1.5$ to 0.5$)$ & 0.30 \\
\hline Days alive and out of hospital through day 30 & $20.9 \pm 6.9$ & $20.7 \pm 7.1$ & $0.2(-0.13$ to 0.53$)$ & 0.16 \\
\hline $\begin{array}{l}\text { Rehospitalization or death from cardiovascular causes - } \\
\text { no./total no. (\%) }\end{array}$ & $372 / 3423(10.9)$ & $402 / 3415(11.8)$ & $-0.9(-2.4$ to 0.6$)$ & 0.24 \\
\hline \multicolumn{5}{|l|}{ Safety end points } \\
\hline Death from cardiovascular causes - no./total no. (\%) & $112 / 3498(3.2)$ & $124 / 3509(3.5)$ & $-0.3(-1.2$ to 0.5$)$ & 0.44 \\
\hline Sudden death from cardiac causes — no./total no. (\%) & $19 / 3324(0.6)$ & $16 / 3327(0.5)$ & $0.1(-0.3$ to 0.4$)$ & 0.61 \\
\hline Hypotension - no./total no. (\%) & $930 / 3498(26.6)$ & $538 / 3509(15.3)$ & $11.3(9.4$ to 13.1$)$ & $<0.001$ \\
\hline Asymptomatic & $748 / 3498(21.4)$ & $436 / 3509(12.4)$ & 9.0 (7.2 to 10.7$)$ & $<0.001$ \\
\hline Symptomatic & $250 / 3496(7.2)$ & $141 / 3509(4.0)$ & $3.2(2.1$ to 4.2$)$ & $<0.001$ \\
\hline $\begin{array}{l}>25 \% \text { decrease in estimated GFR from study-drug initiation - } \\
\text { no./total no. (\%) }\end{array}$ & $1032 / 3289(31.4)$ & $968 / 3278(29.5)$ & 1.09 (0.98 to 1.21$)$ & 0.11 \\
\hline Baseline estimated GFR $<60 \mathrm{ml} / \mathrm{min} / 1.73 \mathrm{~m}^{2}$ & $484 / 1714(28.2)$ & $449 / 1717(26.2)$ & 1.11 (0.96 to 1.3$)$ & 0.16 \\
\hline Baseline estimated GFR $\geq 60 \mathrm{ml} / \mathrm{min} / 1.73 \mathrm{~m}^{2}$ & $548 / 1575(34.8)$ & $519 / 1561(33.2)$ & 1.07 (0.92 to 1.24$)$ & 0.38 \\
\hline
\end{tabular}

* Plus-minus values are means \pm SD. Cl denotes confidence interval, and GFR glomerular filtration rate.

$\uparrow$ Data shown are percentage-point differences, with the exception of data for $>25 \%$ decrease in estimated GFR from study-drug initiation, for which the data shown are odds ratios.

a small effect of nesiritide on dyspnea in most of the participants who received other therapies before and during study-drug infusion; these findings are consistent with the VMAC study results showing a smaller effect of nesiritide as compared with an active control of nitroglycerin, in contrast to nesiritide versus placebo.

In this era of comparative effectiveness assessments, we know little about the comparative effectiveness of standard treatments for acute heart failure, including diuretics, ${ }^{15-19}$ morphine, ${ }^{20}$ inotropic agents, ${ }^{21}$ oxygen, ${ }^{22}$ and vasodilators such as nitroglycerin. ${ }^{15}$

The development of nesiritide poses fundamental questions about the manner in which therapies are developed and assessed. Because nesiritide was not studied in a major outcome trial early in its life cycle, both patients and physicians lacked an appropriate understanding of the proper role of the drug in practice. Our findings also underscore the fact that systematic overviews with small numbers of events can yield unreliable estimates of the balance of benefits and risks, and interpretation of the data is confounded by these imprecise estimates. An updated systematic overview of 30-day mortality data in trials involving patients with acute decompensated heart failure that compared nesiritide with placebo or other control agents showed no adverse effect of nesiritide on survival ${ }^{9}$ (Fig. S4 in the Supplementary Appendix).

This international trial was subject to differing regulatory views regarding the most appropriate analysis plan. According to the primary statistical analysis plan, the effect of nesiritide on dyspnea, although numerically superior, was not significant, whereas analyses required by the European Medicines Agency resulted in a significant result - a divergence that shows the need for better harmonization of regulatory views. ${ }^{23}$ Regardless of which statistical and regulatory plan is considered, the supporting analyses point to a conclusion that is consistent with previous findings. 


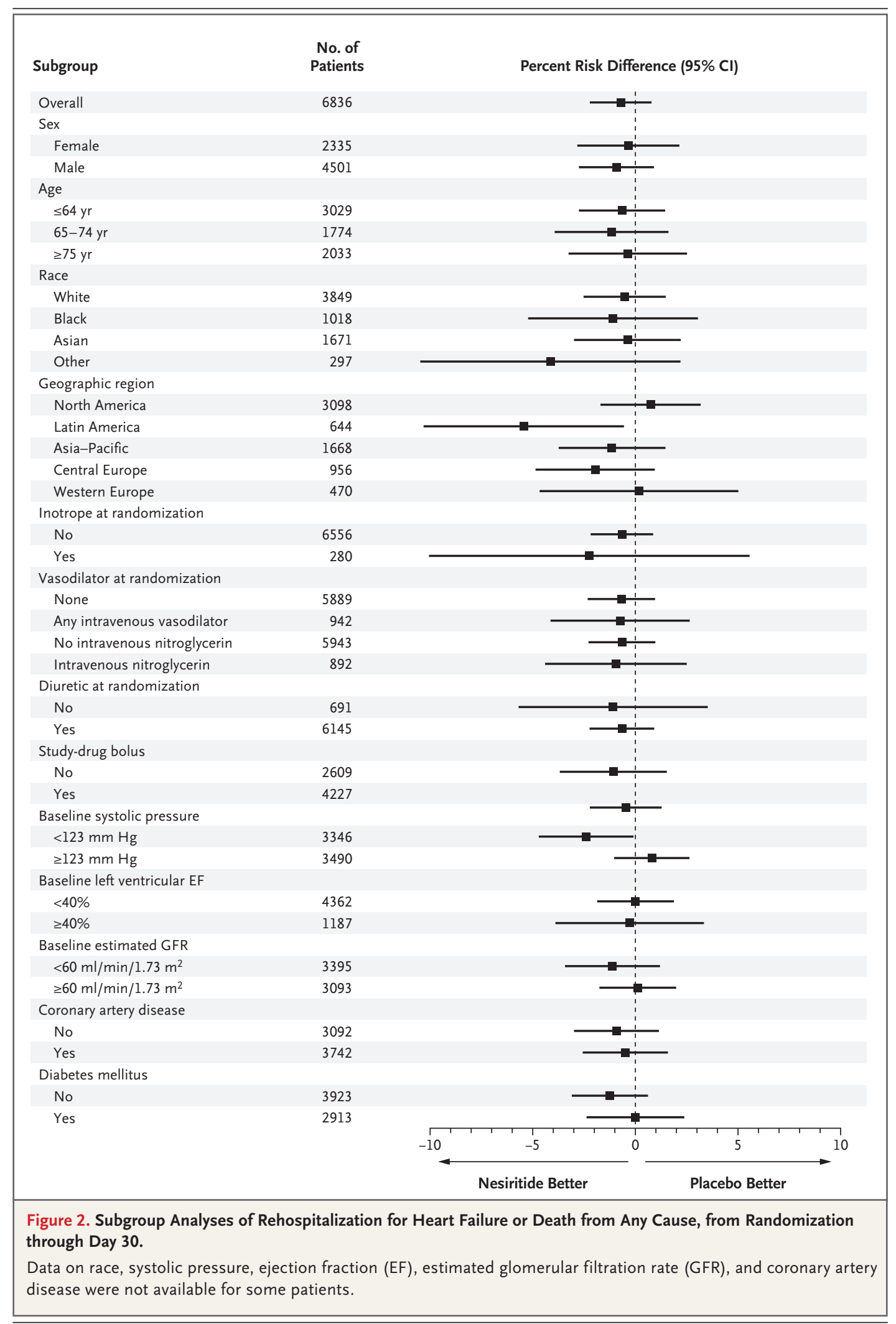

The New England Journal of Medicine 


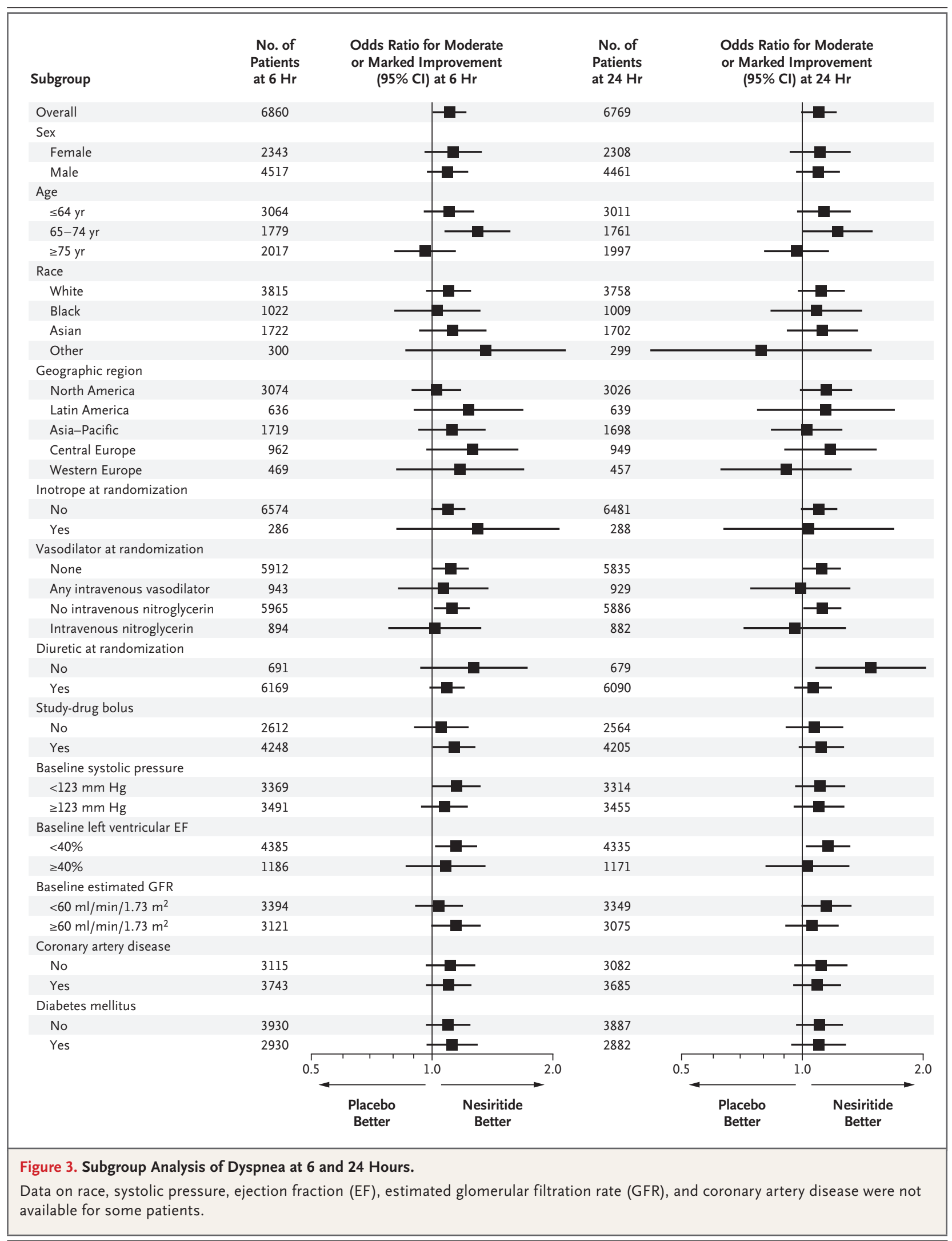

N ENGLJ MED 365;1 NEJM.ORG JULY 7, 2011

The New England Journal of Medicine

Downloaded from nejm.org by Washington Vignolo on August 22, 2011. For personal use only. No other uses without permission. 
Several limitations of this trial should be noted. First, the trial primarily addressed safety concerns; thus, the design was intentionally permissive so that the study population would include a broad range of patients with acute decompensated heart failure. Second, the evaluation of dyspnea remains rudimentary, despite the number of studies that have used the 7-point Likert scale, and the minimal clinically important difference between treated and untreated groups remains unclear. ${ }^{24}$ Third, the clinical-event rate was lower than expected, and in future trials, samples approaching 10,000 subjects would be required to provide greater certainty regarding clinically relevant end points.

In summary, in this study, nesiritide neither increased nor decreased the rate of death and rehospitalization. The observed effect of nesiritide on dyspnea in this trial was small (and not significant) with the coadministration of other ther- apies that relieve congestion. Nesiritide was not associated with worsened renal function, but it was associated with an increase in the rate of hypotension. In hindsight, nesiritide was approved and swiftly adopted in the United States because of its perceived large benefit in relieving dyspnea and congestion, and then its use markedly decreased because of published meta-analyses reporting a detrimental effect on survival and renal function. ${ }^{25}$ Our study showed that neither belief was accurate. The results of this trial highlight the urgent need for rigorously designed trials with adequate power to provide reliable estimates that can replace incomplete or inadequate evidence as a basis for therapeutic decisions.

Presented in part at the 2010 scientific sessions of the American Heart Association, Chicago, November 14-17, 2010. Supported by Scios.

Disclosure forms provided by the authors are available with the full text of this article at NEJM.org.

The authors' full names and degrees are as follows: Christopher M. O'Connor, M.D., Randall C. Starling, M.D., M.P.H., Adrian F. Hernandez, M.D., Paul W. Armstrong, M.D., Kenneth Dickstein, M.D., Ph.D., Vic Hasselblad, Ph.D., Gretchen M. Heizer, M.S., Michel Komajda, M.D., Barry M. Massie, M.D., John J.V. McMurray, M.D., Markku S. Nieminen, M.D., Craig J. Reist, Ph.D., Jean L. Rouleau, M.D., Karl Swedberg, M.D., Kirkwood F. Adams, Jr., M.D., Stefan D. Anker, M.D., Ph.D., Dan Atar, M.D., Alexander Battler, M.D., Rodrigo Botero, M.D., Norman R. Bohidar, Ph.D., Javed Butler, M.D., M.P.H., Nadine Clausell, M.D., Ramón Corbalán, M.D., Maria Rosa Costanzo, M.D., Ulf Dahlstrom, M.D., Ph.D., Lawrence I. Deckelbaum, M.D., Rafael Diaz, M.D., Mark E. Dunlap, M.D., Justin A. Ezekowitz, M.B., B.Ch., David Feldman, M.D., Ph.D., G. Michael Felker, M.D., Gregg C. Fonarow, M.D., Daniel Gennevois, M.D., Stephen S. Gottlieb, M.D., James A. Hill, M.D., Judd E. Hollander, M.D., Jonathan G. Howlett, M.D., Michael P. Hudson, M.D., Robb D. Kociol, M.D., Henry Krum, M.B., B.S., Ph.D., Aleksandras Laucevicius, M.D., Wayne C. Levy, M.D., Gustavo F. Méndez, M.D., Marco Metra, M.D., Sanjay Mittal, M.D., Byung-Hee Oh, M.D., Ph.D., Naveen L. Pereira, M.D., Piotr Ponikowski, M.D., Ph.D., W.H. Wilson Tang, M.D., Supachai Tanomsup, M.D., John R. Teerlink, M.D., Filippos Triposkiadis, M.D., Richard W. Troughton, M.D., Ph.D., Adriaan A. Voors, M.D., Ph.D., David J. Whellan, M.D., Faiez Zannad, M.D., Ph.D., and Robert M. Califf, M.D.

The authors affiliations are as follows: Duke Clinical Research Institute, Duke University Medical Center, Durham (C.M.O., A.F.H., V.H., G.M.H., C.J.R., G.M.F., R.D.K., R.M.C); and the University of North Carolina Heart Failure Program, Chapel Hill (K.F.A.) — both in North Carolina; Cleveland Clinic (R.C.S., W.H.W.T.) and Heart and Vascular Center, MetroHealth Medical Center (M.E.D.) - both in Cleveland; University of Alberta, Edmonton (P.W.A., J.A.E.); Montreal Heart Institute, Université de Montréal, Montreal (J.L.R.); and Dalhousie University, Halifax, NS (J.G.H.) — all in Canada; Stavenger University Hospital, University of Bergen, Bergen, Norway (K.D.); University Pierre and Marie Curie and Hôpital Pitié-Salpêtrière - both in Paris (M.K.); San Francisco Veterans Affairs (VA) Hospital, University of California, San Francisco, and the San Francisco VA Medical Center - all in San Francisco (B.M.M., J.R.T.); Western Infirmary, University of Glasgow, Glasgow, Scotland (J.J.V.M.); Meilahti Hospital, Helsinki (M.S.N.); Department of Emergency and Cardiovascular Medicine, University of Gothenburg, Gothenburg (K.S.); and Department of Medical and Health Sciences, Division of Cardiovascular Medicine, Linkoping University, Linkoping (U.D.) - both in Sweden; Center for Clinical and Basic Research, IRCCS, San Raffaele, Rome (S.D.A.); Applied Cachexia Research, Department of Cardiology, Charité Universitätsmedizin, Berlin (S.D.A.); Aker University Hospital, Oslo (D.A.); Cardiology Department, Rabin Medical Center, Petah Tikva, Israel (A.B.); Clinica Medellin, Medellin, Colombia (R.B.); Johnson and Johnson Pharmaceutical Research and Development, Raritan, NJ (N.R.B., L.I.D.); Cardiology Division, Emory University, Atlanta (J.B.); Serviço de Cardiologia, Hospital de Clínicas de Porto Alegre, Porto Alegre, Brazil (N.C.); Cardiovascular Division, Pontificia Universidad Catolica de Chile, Santiago, Chile (R.C.); Midwest Heart Specialists, Edward Heart Hospital, Naperville, IL (M.R.C.); Estudios Cardiologicos Latino America, Rosario, Argentina (R.D.); Minneapolis Heart Institute, Minneapolis (D.F.); Ahmanson-UCLA Cardiomyopathy Center, Ronald Reagan UCLA Medical Center, Los Angeles (G.C.F.); Janssen Alzheimer Immunotherapy, South San Francisco, CA (D.G.); University of Maryland Hospital, Division of Cardiology, Baltimore (S.S.G.); University of Florida, Gainesville (J.A.H.); Department of Emergency Medicine, University of Pennsylvania (J.E.H.); and Jefferson Medical College, Division of Cardiology (D.J.W.) - both in Philadelphia; Edith and Benson Ford Heart and Vascular Institute, Detroit (M.P.H.); Monash University, and Department of Epidemiology and Preventive Medicine, Alfred Hospital, Prahan, VIC, Australia (H.K.); Vilnius University Hospital, Santariskiu Klinikos, Department of Cardiology and Angiology, Vilnius, Lithuania (A.L.); University of Washington Medical Center, Seattle (W.C.L.); Unidades Medicas de Alta Especialidad Hospital de Especialidades No. 14 Instituto Mexicano del Seguro Social, Veracruz, México (G.F.M.); Department of Cardiology, University of Brescia, Brescia, Italy (M.M.); Department of Cardiology, Escorts Heart Institute and Research Centre, New Delhi, India (S.M.); Department of Internal Medicine, Seoul National University Hospital, Seoul National University College of Medicine, Seoul, South Korea (B.-H.O.); Mayo Clinic, Rochester, MN (N.L.P.); Medical University, Department of Heart Diseases, Military Hospital, Wrocław, Poland (P.P.); Division of Cardiology, Faculty of Medicine, 
Ramathibodi Hospital, Mahidol University, Bangkok, Thailand (S.T.); University Hospital of Larissa, Cardiology Department, Larissa, Greece (F.T.); University of Otago, Christchurch, New Zealand (R.W.T.); University Medical Center Groningen, Groningen, the Netherlands (A.A.V.); and INSERM Centres d'Investigacion Clinique 9501 and U961, Institut Lorrain du Coeur et des Vaisseaux, Centre Hospitalier Universitaire, Nancy, France (F.Z.).

\section{REFERENCES}

1. Lloyd-Jones D, Adams RJ, Brown TM, et al. Heart disease and stroke statistics - 2010 update: a report from the American Heart Association. Circulation 2010; 121(7):e46-e215.

2. Nieminen MS, Brutsaert D, Dickstein K, et al. EuroHeart Failure Survey II (EHFS II): a survey on hospitalized acute heart failure patients: description of population. Eur Heart J 2006;27:2725-36.

3. Bueno $\mathrm{H}$, Ross JS, Wang $\mathrm{Y}$, et al. Trends in length of stay and short-term outcomes among Medicare patients hospitalized for heart failure, 1993-2006. JAMA 2010;303:2141-7.

4. Clarkson PB, Wheeldon NM, Macleod C, Coutie W, MacDonald TM. Brain natriuretic peptide: effect on left ventricular filling patterns in healthy subjects. Clin Sci (Lond) 1995;88:159-64.

5. Colucci WS, Elkayam U, Horton DP, et al. Intravenous nesiritide, a natriuretic peptide, in the treatment of decompensat ed congestive heart failure. N Engl J Med 2000;343:246-53. [Errata, N Engl J Med 2000;343:896, 1504.]

6. Intravenous nesiritide vs nitroglycerin for treatment of decompensated congestive heart failure: a randomized controlled trial. JAMA 2002;287:1531-40. [Erratum, JAMA 2002;288:577.]

7. Zellner C, Protter AA, Ko E, et al. Coro nary vasodilator effects of BNP: mechanisms of action in coronary conductance and resistance arteries. Am J Physiol 1999; 276:H1049-57.

8. Prescribing information, nesiritide (Natrecor). Scios, 2009 (package insert). (http://www.natrecor360.com/sites default/files/natrecor_pi.pdf.)

9. Sackner-Bernstein JD, Skopicki HA, Aaronson KD. Risk of worsening renal function with nesiritide in patients with acutely decompensated heart failure. Circulation 2005;111:1487-91.

10. Sackner-Bernstein JD, Kowalski M, Fox M, Aaronson K. Short-term risk of death after treatment with nesiritide for decompensated heart failure: a pooled analysis of randomized controlled trials. JAMA 2005;293:1900-5.

11. Panel of cardiology experts provides recommendations to Scios regarding Natrecor. (http://www.prnewswire.com.au/cgi-bin/ stories.pl?ACCT $=104 \&$ STORY $=\mid$ www/ story/06-13-2005/0003868886\&EDATE.) URL permanently archived at: http://www .webcitation.org/5zPX5DaBP.

12. Hernandez AF, O'Connor CM, Starling RC, et al. Rationale and design of the Acute Study of Clinical Effectiveness of Nesiritide in Decompensated Heart Failure Trial (ASCEND-HF). Am Heart J 2009; 157:271-7.

13. Ezekowitz JA, Hernandez AF, Starling $\mathrm{RC}$, et al. Standardizing care for acute decompensated heart failure in a large megatrial: the approach for the Acute Studies of Clinical Effectiveness of Nesiritide in Subjects with Decompensated Heart Failure (ASCEND-HF). Am Heart J 2009;157: 219-28.

14. van Elteren $\mathrm{PH}$. On the combination of independent two sample tests of Wilcoxon. Bull Inst Internat Stat 1960;37:35161.

15. Abraham WT, Adams KF, Fonarow $\mathrm{GC}$, et al. In-hospital mortality in patients with acute decompensated heart failure requiring intravenous vasoactive medications: an analysis from the Acute Decompensated Heart Failure National Registry (ADHERE). J Am Coll Cardiol 2005;46:5764.

16. Elkayam U, Tasissa G, Binanay C, et al. Use and impact of inotropes and vasodilator therapy in hospitalized patients with severe heart failure. Am Heart J 2007; 153:98-104.

17. Costanzo MR, Johannes RS, Pine M, et al. The safety of intravenous diuretics alone versus diuretics plus parenteral vasoactive therapies in hospitalized patients with acutely decompensated heart failure: a propensity score and instrumental variable analysis using the Acutely Decompensated Heart Failure National Registry (ADHERE) database. Am Heart J 2007;154: 267-77.

18. Hasselblad V, Gattis Stough W, Shah MR, et al. Relation between dose of loop diuretics and outcomes in a heart failure population: results of the ESCAPE trial. Eur J Heart Fail 2007;9:1064-9.

19. Felker GM, Lee KL, Bull DA, et al. Diuretic strategies in patients with acute decompensated heart failure. N Engl J Med 2011;364:797-805.

20. Peacock WF, Hollander JE, Diercks DB, Lopatin M, Fonarow G, Emerman CL. Morphine and outcomes in acute decompensated heart failure: an ADHERE analysis. Emerg Med J 2008;25:205-9.

21. Cuffe MS, Califf RM, Adams KF Jr, et al. Short-term intravenous milrinone for acute exacerbation of chronic heart failure: a randomized controlled trial. JAMA 2002;287:1541-7.

22. Heart Failure Society of America. Evaluation and management of patients with acute decompensated heart failure. J Card Fail 2006;12(1):e86-e103.

23. Collins SP, Pang PS, Lindsell CJ, et al. International variations in the clinical, diagnostic, and treatment characteristics of emergency department patients with acute heart failure syndromes. Eur J Heart Fail 2010;12:1253-60.

24. West RL, Hernandez AF, O'Connor CM, Starling RC, Califf RM. A review of dyspnea in acute heart failure syndromes. Am Heart J 2010;160:209-14.

25. Hauptman PJ, Schnitzler MA, Swindle J, Burroughs TE. Use of nesiritide before and after publications suggesting drugrelated risks in patients with acute decompensated heart failure. JAMA 2006;296: 1877-84.

Copyright (C) 2011 Massachusetts Medical Society. 